\title{
Erratum to: Ann Hui's Allegorical Cinema
}

\author{
Jessica Siu-Yin Yeung
}

\section{ERRATUM TO:}

Chapter 6 in: J. S. Polley et al. (eds.), Cultural Conflict in Hong Kong, https://doi.org/10.1007/978-981-10-7766-1_6

The reference 'Jameson, Frederic. "Third-World Literature in the Era of Multinational Capitalism.” Social Text 15 (1986): 65-88.' in chapter 6 of 'Filmography' section is moved to 'Bibliography' in the same chapter.

The updated original online version of this book can be found at https://doi.org/10.1007/978-981-10-7766-1_6 